\title{
Integrated Process and Product Design Optimization: a Cosmetic Emulsion Application
}

\author{
Fernando P. Bernardo * and Pedro M. Saraiva \\ GEPSI-PSE Group, Department of Chemical Engineering, University of Coimbra, \\ Pólo II - Pinhal de Marrocos, 3030-290 Coimbra, Portugal
}

\begin{abstract}
A simultaneous approach to address optimal product and process design is presented and applied to a cosmetic lotion case study. The problem formulation integrates product quality, as assessed by customers, a model predicting lotion viscosity as a function of its composition and a process model linking process design and operation with lotion composition and microstructure. The solution of such a problem identifies the optimal lotion composition together with the interrelated process optimal specifications. This integrated design approach is shown to provide better solutions than the ones obtained when product and process design problems are solved separately.
\end{abstract}

Keywords: Process and Product Design, Optimization, Cosmetic Emulsions.

\section{Introduction}

Integrated chemical product and process design may be understood as the specification of a chemical-based product together with the design of the correspondent manufacturing process. The product/process specification should take into account product functionalities and attributes valued by customers, as well as feasibility and profitability of production at a commercial scale. Generic methodologies to guide the solution of such an integrated problem along the way from customer needs to product manufacturing have started to be developed (Cussler and Moggridge, 2001; Wibowo and $\mathrm{Ng}, 2001,2002$ ). The basic idea under these methodologies is to drive decisions by product quality factors related to customer satisfaction, that once identified are then translated to a product/process technical specification.

In a previous work (Bernardo and Saraiva, 2004), and accordingly to the above qualitydriven perspective, we have proposed an optimal design formulation that integrates a product quality function together with product and process models. Based on this optimization problem, and handling its associated uncertainties, we have then presented a method to analyse the value of obtaining additional knowledge regarding a particular problem level. A cosmetic lotion case study was used to illustrate the application of our approach dealing with uncertainties in the prediction of product viscosity, which is correlated with customer satisfaction, but at that stage the interconnected manufacturing process design was not considered.

\footnotetext{
* Corresponding author, e-mail address: bernardo@eq.uc.pt
} 
In this paper, we focus on the simultaneous optimization of product and process design and its application to our previous cosmetic lotion case study, now enlarged with an approximate model of the manufacturing process. Our main objective here is thus to illustrate how both product and process design decisions may interact with each other and therefore verify to what extent an overall formulation that accounts for product quality, as well as process costs, may lead to improved solutions over the common sequential approach, where product and process design are handled separately.

\section{Optimal Product/Process Design Formulation}

Although it may be further generalised, our design formulation is primarily dedicated to consumer formulated products, such as pharmaceutical, cosmetic, and cleansing products. Usually, such products comprise a mixture of several ingredients, combined in a structured system, such as an emulsion, suspension, foam or gel. Table 1 presents a set of variables and parameters relevant to the design of these products.

Table 1. Product/process design variables and parameters.

\begin{tabular}{|c|c|c|}
\hline & Description & Cosmetic Lotion Example \\
\hline$\overline{\mathrm{QF}}$ & Product quality factors valued by customers & Skin feeling \\
\hline$y$ & $\begin{array}{l}\text { Quality variables: product properties } p \text { or states } x \\
\text { related to quality factors }\end{array}$ & Lotion viscosity \\
\hline$p$ & $\begin{array}{l}\text { Product physicochemical properties or effects } \\
\text { during usage }\end{array}$ & Lotion viscosity \\
\hline$d_{1}$ & $\begin{array}{l}\text { Product design variables (process independent): } \\
\text { ingredients used and their proportion }\end{array}$ & $\begin{array}{l}\text { Oil-in-water emulsion (water, } \\
\text { thickener, oil, emulsifier, etc) }\end{array}$ \\
\hline$x_{1}$ & $\begin{array}{l}\text { Product state variables (process dependent): } \\
\text { product structure }\end{array}$ & $\begin{array}{l}\text { Droplet size distribution of the oil- } \\
\text { phase }\end{array}$ \\
\hline$z_{1}$ & $\begin{array}{l}\text { Product operating variables: external conditions } \\
\text { during product usage }\end{array}$ & $\begin{array}{l}\text { Shear rate of lotion application on } \\
\text { skin }\end{array}$ \\
\hline$d_{2}$ & $\begin{array}{l}\text { Process design variables: flowsheet } \\
\text { configuration and equipment dimensions }\end{array}$ & Mixing equipment dimensions \\
\hline$z_{2}$ & $\begin{array}{l}\text { Process operating variables: operating procedure } \\
\text { (recipe) and equipment operating conditions }\end{array}$ & Impeller speed \\
\hline$\theta_{2}$ & $\begin{array}{l}\text { Process parameters: physicochemical properties } \\
\text { and kinetic/equilibrium parameters }\end{array}$ & $\begin{array}{l}\text { Heat transfer coefficient in } \\
\text { mixing/heating tank }\end{array}$ \\
\hline$\theta_{3}$ & $\begin{array}{l}\text { Additional parameters, such as economic } \\
\text { coefficients or market indicators }\end{array}$ & $\begin{array}{l}\text { Quality loss coefficient, electricity } \\
\text { cost }\end{array}$ \\
\hline
\end{tabular}

Our design methodology is therefore based on three main groups of relationships:

1. The quality function, relating quality factors $\mathrm{QF}$ with product quality variables $y$;

2. The product function, which predicts product properties as a function of its related variables:

$p=f_{1}\left(d_{1}, x_{1}, z_{1}\right)$;

3. The process function, linking product and process variables:

$f_{2}\left(d_{1}, d_{2}, z_{2}, \theta_{2}, x_{1}\right)=0$.

Regarding quality functions, we will assume here that, for each $y$ variable, there is an optimal $y^{*}$ value, from the customer point of view, and that the quality loss $L$ associated with a deviation $\left(y-y^{*}\right)$ is well quantified by a Taguchi loss function: 
$L=k\left(y-y^{*}\right)^{2}$,

where $k$ is a quality loss coefficient to be estimated based on customer satisfaction surveys and panels. Other quality function definitions may be used as an alternative and are easily incorporated in the proposed methodology.

Given the above mappings, leading all the way from customer perceptions to process operating conditions, our integrated product/process design problem can then be formulated as follows:

$$
\begin{aligned}
& \max _{d_{1}, d_{2}, z_{2}} P\left(d_{1}, x_{1}, z_{1}, p, d_{2}, z_{2}, \theta_{2}, \theta_{3}\right) \\
& \text { s.t. } p=f_{1}\left(d_{1}, x_{1}, z_{1}\right) \wedge g_{1}\left(d_{1}, x_{1}, z_{1}, p\right) \leq 0 \\
& \quad f_{2}\left(d_{1}, d_{2}, z_{2}, \theta_{2}, x_{1}\right) \wedge g_{2}\left(d_{1}, d_{2}, z_{2}, \theta_{2}, x_{1}\right) \leq 0 .
\end{aligned}
$$

Here, $P$ stands for an overall performance criterion, including a quality cost term based on loss functions (3) and also production and investment costs; $g_{1} \leq 0$ and $g_{2} \leq 0$ represent respectively product and process inequality constraints. A multi-criteria optimization approach can also be adopted, with product quality and process costs being handled as two opposing objectives and the trade-offs between them evaluated.

\section{A Cosmetic Lotion Case Study}

A cosmetic lotion is usually an oil-in-water emulsion with the typical formulation shown in Table 2 (Williams and Schmitt, 1992; Wibowo and Ng, 2001). The lotion main function is to maintain the skin hydrated, by adding water from its own composition and reducing water loss from skin due to occlusive ingredients, such as mineral oils and fatty acids, and also humectants, such as glycerol. Emulsifiers that adsorb at the surface of oil droplets promote emulsion formation and stability, lowering the oil/water interfacial tension. Thickener additives, usually water-soluble polymers, largely control emulsion flow properties and also contribute to its stability, by increasing the continuous phase viscosity.

Table 2. Typical formulation of a hand and body lotion.

\begin{tabular}{lr|lr}
\hline Part A (10 to 15\% (v/v) of the total) & $\%(\mathrm{w} / \mathrm{w})$ & Part B & $\%(\mathrm{w} / \mathrm{w})$ \\
\hline Stearic acid (occlusive) & 25.5 & Deionized water (solvent) & q.s. \\
Cetyl alcohol (occlusive) & 10.3 & Glycerol (humectant) & $5-12$ \\
Petrolatum USP (occlusive) & 10.3 & Xanthan gum (thickener) & $0.5-1.5$ \\
Mineral oil, 70 mPa.s (occlusive) & 20.5 & & 100 \\
Isopropyl palmitate (occlusive) & 20.5 & Part C ( 0.25\%(w/w) of the total) \\
Glyceryl monostearate (emulsifier) & 10.3 & Preservatives \\
PEG-40 stearate (emulsifier) & 2.6 & Fragrances \\
\cline { 2 - 2 } & 100 & & \\
\hline
\end{tabular}

\subsection{Quality Function}

Lotion quality primarily depends upon its hydrating effect, but also relies on other factors, such as stability, flow properties and several sensorial attributes. Here, we will focus our product quality characterization strictly around the sensations experienced during its application on skin, the so-called skin feeling. 
Sensory panel tests (Brummer and Godersky, 1999), discriminated in sensations at the beginning and end of lotion application, indicate a significant correlation between these two quality factors and the correspondent viscosities $\mu_{1}$ and $\mu_{2}$ (quality variables). From such results, two loss functions (3) are constructed, with ideal values $\mu_{1} *=375$ and $\mu_{2}{ }^{*}=0.0242$ Pa.s, and both losses $L_{1}$ and $L_{2}$ measured in \% of product lost value.

\subsection{Product Function}

The main variables determining lotion viscosity are: thickener (xanthan gum) content in the aqueous phase $\left(w_{\mathrm{T}}\right)$, glycerol content in the aqueous phase $\left(w_{\mathrm{G}}\right)$ and oil-phase volume fraction $(\phi)$. These are product design variables $\left(d_{1}\right)$ to be optimized, under the limits shown in Table 2, while the rest of the lotion formulation is considered fixed.

For the viscosity of xanthan gum aqueous solutions, experimental data are available showing that three different regions may be distinguished: an approximately Newtonian region, for lower shear rates, followed by a strong shear-thinning region, and then again a nearly Newtonian region for high shear rates (Pal, 1995). These data are fitted to a Carreau model (Tanner, 2000), in which the glycerol contribution is incorporated assuming that it only influences the limiting viscosity for high shear rates. One thus obtains a model that predicts continuous (aqueous) phase viscosity: $\mu_{\mathrm{c}}=\mu_{\mathrm{c}}\left(w_{\mathrm{T}}, w_{\mathrm{G}}, \gamma\right)$. The theoretical model of Yaron and Gal-Or $(\mathrm{Pal}, 2001)$ is then used to predict emulsion viscosity from single-phase individual viscosities: $\mu=\mu\left(\mu_{\mathrm{c}}, \mu_{\mathrm{d}}, \phi\right)$, where $\mu_{\mathrm{d}}$ stands for the oil-phase (Newtonian) viscosity. Our resulting product function is then of the form: $\mu=f_{1}\left(w_{\mathrm{T}}, w_{\mathrm{G}}, \phi, \gamma\right)$.

In order to estimate quality variables $\mu_{1}$ and $\mu_{2}$, the correspondent shear rate of lotion application must be known. For oil-in-water lotions, the typical final shear rate is $\gamma_{2}=$ $5000 \mathrm{~s}^{-1}$. The initial shear rate $\gamma_{1}$ is calculated as the transition point between the nearly Newtonian region for low shear rates and the strong shear-thinning region.

\subsection{Process Function}

A batch process is considered (Figure 1) comprehending the following operations (Williams and Schmitt, 1992; Wibowo and Ng, 2001):

1. In tank T-1: (i) charge part A; (ii) dissolve solids, heat and mix;

2. In tank T-2: (i) charge part B; (ii) heat and mix; (iii) add part A; (iv) cool and mix (pre-emulsion formation); (v) add part $\mathrm{C}$ and mix;

3. Homogenization in colloid mill CM-1 (continuous operation);

4. Filling and packaging.

Besides mass and energy balances, our process model includes droplet breakage relationships (Shimizu et al., 1999; Wieringa et al., 1996) that predict the maximum droplet diameter at the exit of tank T-2 $\left(D_{2, \max }\right)$ and after homogenisation in the colloid mill $\left(D_{3, \max }\right)$. These droplet sizes correspond to an equilibrium situation of maximum size reduction and the time necessary to attain such a state is also estimated.

The overall process model has the following structure: inputs $-d_{1}$ (product design variables), $d_{2}$ (batch size and equipment dimensions), $z_{2}$ (operating temperatures and mixing speeds) and $\theta_{2}$ (process parameters); outputs $-D_{3, \max }$ (product state variable), operating times and energy consumptions. Given the annual production required, and assuming some process scheduling data, the effective batch time (time between two consecutive batches) and the annual operating time are also estimated. 


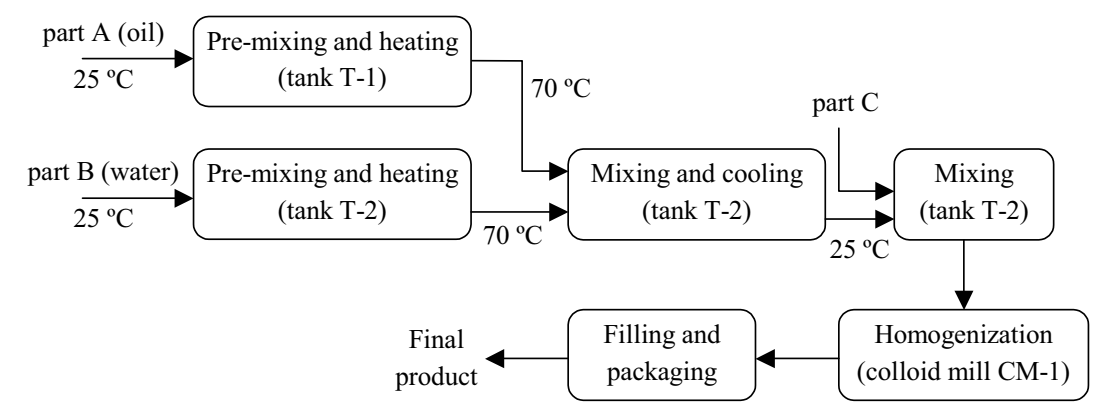

Figure 1. Lotion manufacturing process.

\subsection{Integrated Product/Process Design}

Our integrated product/process design problem is therefore formulated as follows: given the annual production required, find $d_{1}, d_{2}$ and $z_{2}$ that minimize an overall annual cost, equal to the sum of investment, production and quality loss costs. Quality costs are considered proportional to the total loss $\left(L_{1}+L_{2}\right)$ and estimated as $30 \%$ of production costs when $\left(L_{1}+L_{2}\right)=25 \%$.

Operating temperatures are not optimized, since the process model at this stage does not incorporate the dependence of interfacial tension with temperature. Therefore, temperatures are considered fixed and equal to the values shown in Figure 1.

Since the adopted quality function does not include the effect of droplet size, which is known to be related with product stability and smoothness, a restriction $D_{3, \max } \leq \alpha$ is imposed, and the problem solved for different values of $\alpha$. In order to guarantee a sufficiently refined pre-emulsion, the constraint $D_{2, \max } \leq 200 \mu \mathrm{m}$ is also considered. The optimization problem is implemented and solved using GAMS/CONOPT3.

\subsection{Results and Discussion}

Figure 2a shows a set of optimal solutions obtained for an annual production of 2000 ton/yr and for different $\alpha$ values $\left(D_{3, \max } \leq \alpha\right)$. The rise in total cost is mainly due to the process intensification, namely as a result of an increase in colloid mill dimensions. Quality loss essentially remains the same, which means that the optimal product formulation does not change when the production of a thinner emulsion is imposed. For $\alpha \leq 6 \mu \mathrm{m}$, the process becomes infeasible.

Let's consider now that a more concentrated emulsion is allowed for $(\phi \leq 0.2)$. In this case, both optimal product and process decisions are affected by the $\alpha$ value. When a thinner emulsion is imposed, the optimal solution adjusts product composition in order to alleviate the process, with a consequent increase in quality loss (Figure 2b).

We also compare the results obtained when the product and process design problems are solved simultaneously and separately, in particular for $\phi \leq 0.2$ and $\alpha=10 \mu \mathrm{m}$ (Table 3). The design resulting from a decoupled solution (product design followed by process design) corresponds to higher investment and production costs, although the differences found are not very high. However, it should be noted that such differences become more significant as $\alpha$ decreases. 
Table 3. Simultaneous versus decoupled product/process design solutions.

\begin{tabular}{lccccccc}
\hline & $w_{\mathrm{T}}$ & $w_{\mathrm{G}}$ & $\phi$ & \multicolumn{4}{c}{ Costs (thousand Euro/yr) } \\
\cline { 5 - 8 } & $(\% \mathrm{w} / \mathrm{w})$ & $(\% \mathrm{w} / \mathrm{w})$ & & Investment & Production & Quality & Total \\
\hline Simultaneous & 0.8454 & 12.00 & 0.1813 & 86.8 & 244.2 & 2.0 & 333.0 \\
Decoupled & 0.8515 & 12.00 & 0.1667 & 88.3 & 247.1 & 0.0 & 335.4 \\
\hline
\end{tabular}

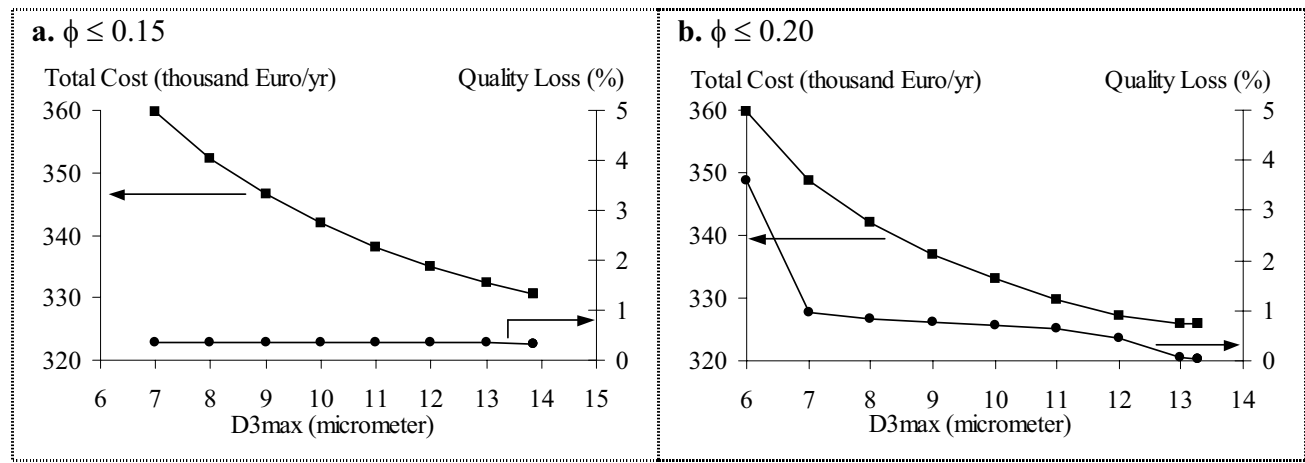

Figure 2. Optimal solutions for different emulsion droplet sizes

\section{Conclusions}

We have presented an integrated product/process optimal design formulation and applied it to a cosmetic lotion case study. The results obtained clearly illustrate how decisions regarding product formulation and structure interact with process design and operation, as well as how a decoupled sequential solution of product and process design problems may lead to suboptimal solutions. Therefore, an integrated point of view seems to provide a much sounder approach for addressing this kind of problems.

\section{References}

Bernardo, F. P. and Saraiva, P. M., 2004, Computer-Aided Chemical Engineering, BarbosaPóvoa, A. and Matos, H. (eds.), 18, 151.

Brummer, R. and Godersky S., 1999, Colloids \& Surfaces A: Physicochem. Eng. Aspects 152, 89. Cussler, E. L. and Moggridge, G. D., 2001, Chemical Product Design, Cambridge University

Press, Cambridge.

Pal, R., 1995, AIChE J. 41, 783.

Pal, R., 2001, Chem. Eng. Journal 81, 15.

Shimizu, K., Minekawa, K., Hirose, T. and Kawase, Y., 1999, Chem. Eng. Journal 72, 117.

Tanner, R. I., 2000, Engineering Rheology, $2^{\text {nd }}$ ed., Oxford University Press, Oxford.

Wibowo, C. and Ng, K. M., 2001, AIChE J. 47, 2746.

Wibowo, C. and Ng, K. M., 2002, AIChE J. 48, 1212.

Wieringa, J. A., van Dieren, F., Janssen, J. J. M. and Agterof, W. G. M., 1996, Trans. IChemE. 74, part A, 554.

Williams, D. F. and Schmitt, W. H., Eds., 1996, Chemistry and Technology of the Cosmetics and Toiletries Industry, $2^{\text {nd }}$ ed., Blackie Academic \& Professional, London.

\section{Acknowledgements}

The authors acknowledge financial support provided by FCT through research project POCTI/EQU/32647/2000. 